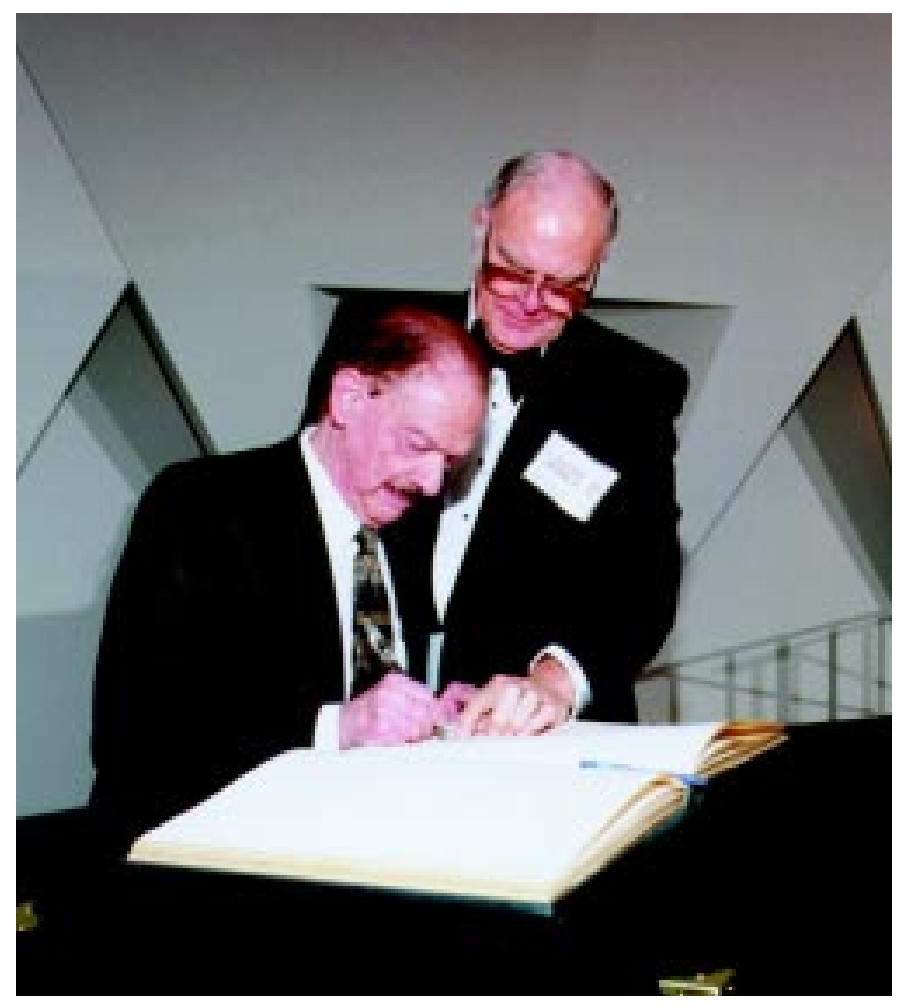

\title{
News
}

\section{New Brazilian member of the USA National Academy of Sciences}

Francisco M. Salzano, Emeritus Professor of the Genetics Department, Biosciences Institute, Federal University of Rio Grande do Sul, was indicated last years as a Foreign Member of the prestigious United States National Academy of Sciences. From April 29 to May 2 of this year he attended the Academy's Annual Meeting, participating in the first day of the formal induction ceremony, with the signing of the Book of Membership. On May 1 he presented a brief, 15-min talk to the Anthropology Section about his present research interests.

The USA National Academy is formed by a selected group of 2,232 members, of whom 1,927 are US citizens. The remaining 302 are constituted by foreign associates from 38 countries, representing all fields of science. Twelve of them are from Latin America. Up to the present, only two Brazilians were awarded this honor, and both are geneticists, Prof. Warwick E. Kerr (Department of Genetics and Biochemistry, Federal University of Uberlândia) and now Prof. Salzano. 
